\title{
RECONSTRUYENDO EL TEJIDO SOCIAL DESDE LA FE Y LA PARTICIPACIÓN SOCIO-POLÍTICA. BALANCE DE LAS COMUNIDADES ECLESIALES DE BASE EN NAYARIT, MÉXICO
}

\section{RECONSTRUCTING SOCIAL CONTEXT FROM FAITH AND THE SOCIO-POLITICAL PARTICIPATION. BALANCE IN BASIC ECCLESIAL COMMUNITY IN NAYARIT, MÉXICO}

\author{
Pedro Orozco Espinosa* \\ Alejandro Enrique Orozco Morales**
}

RESUMEN

\begin{abstract}
Este artículo reconstruye la experiencia de organización social de las Comunidades Eclesiales de Base (СЕB) en Nayarit (México), durante la década de los 80 y 90 del siglo pasado. En especial, se enfatiza su rápida configuración como catalizador y potenciador de diferentes acciones que se desarrollaron en un nuevo tejido social en la entidad. Asimismo, se pretende realizar un breve balance para explicar no solo su éxito relativo, sino su decadencia en la reconstrucción del tejido social en estos lugares.
\end{abstract}

PALABRAS CLAVE: MÉXICO * RELIGIÓN * SOCIEDAD CIVIL * PARTICIPACIÓN SOCIAL * PARTICIPACIÓN POLÍTICA * MOVIMIENTOS SOCIALES

\section{ABSTRACT}

This article reconstructs the experience of social organization CEB in Nayarit, during the decade of the 80's and 90's of last century. In particular, the shooting settings be emphasized as a catalyst and enabler for various actions that took place in a new social tissue in the body. It is also intended to make a brief overview to explain not only their relative success, but its decline in the reconstruction of the social fabric in these places.

KEYWORDS: MÉXICO * RELIGION * CIVIL SOCIETY * SOCIAL PARTICIPATION * POLITIC PARTICIPATION * SOCIAL MOVEMENTS

Área de Ciencias Sociales y Humanidades de la Universidad Autónoma de Nayarit, México. hechizobr@yahoo.com.

** Área de Ciencias Sociales y Humanidades de la Universidad Autónoma de Nayarit, México. alejandro.orozco.morales@gmail.com. 


\section{FUNDAMENTO Y JUSTIFICACIÓN DE LAS CEB}

En las llamadas Comunidades Eclesiales de Base (СЕB) existen realidades muy similares, semejantes en pobreza $y$ condiciones materiales poco propicias para un buen desarrollo; sin embargo, también se destaca la particularidad que les viene por su riqueza cultural, producto de su situación contextual. Las llamadas CEB emergen tanto en áreas urbanas como rurales, pero con los elementos en común que las configuran: su sencillez, su sintonía con el Jesús histórico, su opción incondicional por los pobres, que no solo es una actitud solidaria con estas personas, sino también un rechazo de la situación de pobreza y las causas que la producen. Estas características han hecho aparecer a las CEB como comunidades propositivas $y$ activistas, que hacen eco de su misión profética ${ }^{1}$ y se vuelven críticas de las estructuras de opresión ${ }^{2}$. Se trata de la celebración fraterna de la fe y la vida, con el propósito de trabajar juntos para hacer presente y construir el Reino de Dios ${ }^{3}$, influyendo en la transformación de las realidades sociales y políticas del contexto en que viven.

El trabajo de las CEB consiste en la reconstrucción de la Iglesia a partir de su experiencia y su tradición originaria, es decir, la recuperación de la matriz histórica misma desde los orígenes y el carácter comunitario del movimiento de Jesús y de las primeras comunidades cristianas, de frente a la situación concreta del ejercicio de su misión. Por lo que

1 La misión profética se remonta a la visión de los Profetas del Antiguo Testamento, la cual es recuperada por Jesús y que es asumida con radicalidad por las primeras comunidades cristianas. Posteriormente, la Iglesia toma esta actitud como parte fundamental de su misión en el Mundo.

Paul Ricoeur decía: "no estamos verdaderamente con los pobres, si no estamos contra la pobreza". Cfr. Gutiérrez, 2007. las CEB intentan recuperar el origen mismo y pneumático ${ }^{4}$ de la Iglesia y la experiencia más antigua de inculturación del Evangelio, viviendo la fe desde la construcción de la comunidad como estilo prioritario y esencial de hacer Iglesia, desde la vida y el compromiso con los pobres y marginados, por quienes optó Jesús. Un proyecto de inclusión, frente a las exclusiones existentes en todos los tiempos.

Las CEB encuentran una sintonía, al inicio de sus trabajos, en la estructura misma de la Iglesia, para algunos tradicional y jerárquico. Por ello, estas han encontrado su fundamento en la misma renovación de la Iglesia, desde el Concilio Ecuménico Vaticano II, las Conferencias Episcopales Latinoamericanas de Medellín y Puebla, pero también en la Doctrina o Enseñanza Social de la Iglesia, con especial interés en la reflexión de la Teología de la Liberación. Estos elementos son los que aportan no solo el origen y génesis de las CEB, sino sobre todo los diferentes caminos que se configuran en su inserción y actuación social.

Hay que partir de una referencia histórica actual: el Concilio Vaticano II, acontecimiento que sensibiliza sobre los desafíos del mundo $y$ exhorta a asumir un compromiso con todos los hombres y mujeres de todos los tiempos, especialmente de los más pobres ${ }^{5}$. Sin embargo, es necesario precisar que en este Concilio se sientan las bases de la necesidad de una renovación profunda en la misión de la Iglesia y la revisión del papel de los laicos ${ }^{6}$ en el mundo actual; es decir, una vuelta a sus orígenes en las primeras comunidades cristianas.

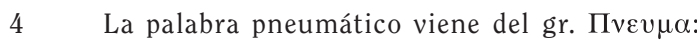
Espíritu; เкๆ: relativo a. (Lo relativo al Espíritu). En la teología cristiana, este concepto se utiliza para designar que la acción de la comunidad (iglesia) está inspirada y guiada por el Espíritu Santo, quien concede una gran diversidad de carismas (dones), que se ponen al servicio de los demás. Por lo tanto, la vida de la comunidad es un constante discernimiento en el espíritu a fin de ayudar a resolver las antinomias o contradicciones de la comunidad y de la sociedad, $y$ así construir el Reino de Dios o su proyecto de vida para la humanidad.

5 Gaudium et Spes (GS). Nro. 1.

6 Lumen Gentium (LG). Nro. 30. Jér jesús histórico y posteriormente, por tianas. Cfr. Pastor, 2008. 
Así, a partir del Vaticano II, se convocó a las Iglesias particulares de América Latina, a concretar lineamientos pastorales desde sus situaciones histórico-sociales. Esto dio origen a cuatro Conferencias Episcopales Latinoamericanas, de las cuales dos de ellas, Medellín y Puebla, fueron importantes para potenciar aún más a las CEB y para mostrar la realidad de pobreza e injusticia en América Latina, $y$ afianzar este modelo en las particularidades de las Iglesias locales.

En la Conferencia Episcopal Latinoamericana de Medellín (Colombia 1968) se denuncia las estructuras sociales y económicas que generan pobreza y se lanza un llamado a promover la justicia social ${ }^{7} y$ con ello, se pide promover la experiencia comunitaria desde la Base ${ }^{8}$. En Puebla (México 1979), la evaluación pastoral de América Latina es de abundantes frutos, por lo que ratifica y respalda este gran esfuerzo de las СEB por hacer presentes su misión en condiciones históricas de extrema pobreza. Es por ello, que la Conferencia Episcopal lanza con más fuerza su voz a favor de los pobres al punto de considerarlos como su opción preferencial en la misión de la evangelización ${ }^{9}$.

Sin duda, en Puebla se reafirma lo que para en Medellín era esperanza: la constatación de la realidad cruda de América Latina ${ }^{10}$ y un compromiso por transformar esas condiciones, sobre todo, de los más vulnerables. Así, la década de los 70 del siglo pasado fue una clara manifestación de esperanza. Es evidente, entonces, que la Iglesia latinoamericana se convertiría en " $\mathrm{voz}$ de aquellos que no tienen voz"11. Sin embargo,

$7 \quad$ En el documento de Medellín, la justicia social es entendida como concepción de vida y como impulso hacia el desarrollo integral de todos los pueblos $(1,5)$. Así, la justicia y la paz se conquistan por una acción dinámica de concientización y de organización de los sectores populares, capaz de urgir a los poderes públicos, muchas veces impotentes en sus proyectos sociales $(2,18)$.

$8 \quad$ Medellín 6, 10, 11, 13, 15.

$9 \quad$ Puebla nro. 96, 641-643, 1153-1156.

10 Ídem.

11 Ídem. También, Homilía 29 de julio de 1979 "Mons. Oscar Arnulfo Romero. Su pensamiento", vol. vII, p. 118. también fue cierto que no gozó de la simpatía desde Roma. No es un secreto que al inicio de su pontificado, el papa Juan Pablo II vio en las CEB, células inspiradas en la ideología marxista y por ende, era necesario tomar con ciertas reservas el trabajo que desempeñaban en las iglesias particulares. Por ejemplo, los trabajos pastorales de las Diócesis de Chiapas y Oaxaca.

En este contexto, la Congregación para la Doctrina de la $\mathrm{Fe}^{12}$, bajo el liderazgo del Cardenal Joseph Ratzinger, en ese momento, publicó dos exhortaciones sobre la Teología de la Liberación (1984 y 1986), en las cuales marcó el inicio de una etapa de sospecha $y$ de ataques a las diócesis, donde el papel de las СЕB se encontraban como configuradoras de la fe y del tejido social. De modo que las décadas siguientes y los primeros años del tercer milenio, fueron años de fuertes ataques a las CEB. Así, de la sospecha se pasó a la crítica y de esta a la indiferencia.

Algunas diócesis (como la de Tepic, Ciudad Guzmán, Colima o algunas parroquias de la Arquidiócesis de Guadalajara) que trabajaban en este modelo de Iglesia, se retiraron y cambiaron de opción o simplemente desaparecieron, otras resistieron, aunque ya no con el mismo ímpetu, pues obispos y sacerdotes les retiraron su apoyo y en algunos casos, las fueron agotando hasta reducirlas ${ }^{13} 0$ transformarlas en otro tipo de movimiento eclesial, por ejemplo, en Movimiento de Renovación en el Espíritu Santo.

12 Originalmente era llamada Sagrada Congregación de la Romana y Universal Inquisición. Fue fundada por Pablo III en 1542 con la Constitución "Licet ab initio", para defender a la Iglesia de las herejías. En 1908, el Papa San Pío X cambió su nombre por el de Sagrada Congregación del Santo Oficio. Finalmente, en 1965, recibió el nombre actual bajo el Pontificado de Pablo vi. Hoy, según el art. 48 de la Constitución Apostólica sobre la Curia Romana "Pastor Bonus", promulgada por el Santo Padre Juan Pablo II el 28 de junio de 1988, la tarea propia de la Congregación para la Doctrina de la Fe es promover $y$ tutelar la doctrina de la fe $y$ la moral en todo el mundo católico. Por esta razón, todo aquello que de alguna manera toca este tema, cae bajo su competencia.

13 Puede ser el caso de las CEB en Tepic, Ciudad Guzmán, Colima, la Arquidiócesis de Guadalajara, entre otras (Rowland, 2000). 
Las dos Conferencias posteriores, Santo Domingo y Aparecida, en Brasil (1992 y 2007, respectivamente), se caracterizaron por orientar el Espíritu de estas comunidades en otro sentido, es decir, se les reconoció solamente como escuelas misioneras y como primeras células de estructuración eclesial, foco de fe y evangelización ${ }^{14}$. En concreto, se está ante una profunda transformación de la mirada que se tenía, reduciéndolas exclusivamente al asunto de la fe $y$ en menor medida a las críticas y a las acciones sociales.

Las Teologías de la Liberación (TDL) ${ }^{15}$, sin duda, jugaron un papel importante en la configuración de las CEB, ya que fueron dando orientación, contenido y forma a la dinámica misma de las comunidades encontradas en las distintas iglesias locales.

Las TDL tiene sus antecedentes en los años 70 del siglo pasado, con teólogos laicos y clérigos, como el peruano Gustavo Gutiérrez, uno de los consultores en Medellín y presente en el documento sobre la Pobreza en la Iglesia (Berryman 1990); los brasileños y hermanos Leonardo y Clodivis Boff, el chileno Segundo Galilea, el uruguayo Juan Luis Segundo, el chileno-costarricense Pablo Richard y el hispano-salvadoreño Jon Sobrino. Asimismo, por su tendencia ecuménica, se encuentran teólogos protestantes como el brasileño Rubén Alves (presbiterano), el argentino José Míguez Bonino (metodista y evangélico de formación), Jorge Pixley (pastor bautista) y el costarricense Víctor Araya (metodista), entre otros. Todos ellos, por sí mismos, pueden ser profundizados por sus matices y sus coincidencias, al compartir su indignación por la realidad social existente en América Latina. Estos mismos teólogos subrayan también las dimensiones políticas de la fe $y$ no solo como doctrina o enseñanza social de la Iglesia, sino como una actitud constante de crítica social ${ }^{16}$.

14 Santo Domingo nro. 61, 95, 259. Aparecida nro. 178, 193.

15 Se utilizará TDL para referirse a las Teologías de la Liberación (Romo, 2007).
Las TDL tienen su importancia por su radicalidad ante las exigencias del evangelio, de modo que consideran que la fe siempre se acompaña por las obras que conducen a la transformación social, es decir, la reivindicación de los derechos de los pobres. Así que no se trata de ayudar a los pobres de manera asisten$\mathrm{cial}^{17}$, sino de cambiar las estructuras y el sistema que provoca la pobreza, por lo que se llama a una lucha de liberación. En su momento lo expresó Ignacio Ellacuría acerca de la situación de El Salvador en 1970 y 1980, donde aceptó incluso el uso de la fuerza. De esta manera, a esta teología, Richard (1995) la llama "Teología de la Vida", que va contra este capitalismo salvaje $y$ excluyente, pues "asume el criterio de vida para todos y de vida para el cosmos, como criterio para definir la misma vida o la esencia de Dios" (1995, 130-131).

Entonces, para las TDL, las CEB se plantean como forma de organización eclesial, que son grupos de 15 a 20 personas entre religiosos y laicos que se reúnen para meditar la Palabra de Dios, orar y hacer obras sociales entre los pobres. En estas comunidades que no hay separación entre la Iglesia y el mundo, por ello, no ve el Reino de Dios en el cielo cuando nos morimos, sino como una construcción que se inicia en este mundo $y$ que tiene por objeto el logro de la justicia y la solidaridad. Esta forma de actuar se diferencia, contrasta $y$ confronta mucho de la pastoral de masas del catolicismo tradicional o de la teología habitual. Por ello, Boff (1988) considera que su naturaleza se encuentra en que la Iglesia como base del Pueblo, encarna la importancia liberadora de la fe en el mundo, portadoras de Buena Nueva a través de su participación en los ministerios y en los sacramentos. Además, trascienden lo religioso para hacer cristianos nuevos y ciudadanos críticos en busca de una nueva esperanza social (Boff 1988).

Con esto, resulta evidente que la lectura del texto bíblico enfatiza los elementos que muestran la indignación de la pobreza, pero a

$17 \quad$ Esta es una acción de la Iglesia por parte de Cáritas Diocesana o por los grupos apostólicos locales, ej. Acción Católica. 
su vez una posible opción ${ }^{18}$. Así, la base de análisis de la Biblia es la opción preferencial por los pobres y la radicalidad del seguimiento y misión de Jesús. Por tanto, el mensaje implica la liberación espiritual y material dentro de la historia.

Un aporte significativo en términos de generación de conocimiento es que las TDL dieron impulso al método inductivo, en contraposición al método deductivo que había predominado durante siglos en la reflexión teológica ${ }^{19}$. Este método parte desde abajo, tratando de conocer y analizar la realidad en toda su complejidad para después emitir juicios $y$ criterios de discernimiento sobre esa misma realidad. A este método se le ha denominado como el método "Ver, Juzgar y Actuar" (Berryman 1990) ${ }^{20}$. Es decir, la comunidad toma como punto de partida el análisis de la realidad (ver), la cual es iluminada con la Palabra de Dios desde una perspectiva liberadora (juzgar) $y$ finalmente, se llega a las propuestas de los compromisos pastorales (actuar). Cabe añadir que este proceso y estos compromisos se ven simbólica y ritualmente encarnados en la celebración litúrgica o en la eucaristía.

\section{LAS CEB EN AMERICA LATINA Y MÉXICO}

\section{AMERICA LATINA}

El aporte central de las СЕB en América Latina, se encuentra en generar una nueva reflexión teológica, articulada con la realidad,

18 De ahí que se parte del estudio del libro del Éxodo donde los oprimidos son liberados. En el Nuevo Testamento se interesa mucho en la práctica y la predicación de Jesús respecto al Reino de Dios, con lo que se observa que la práctica de Jesús está a favor de los pobres y los oprimidos.

19 Aunque dicho método venía enunciado y aplicado en el esquema de la Encíclica Populorum Progressio y las Conferencias Episcopales Latinoamericanas, Medellín y Puebla, no así en el documento de Santo Domingo, mientras que en Aparecida aparece disperso y desordenado.

20 Este método tiene su raíz histórica en el método jocista por su creador José Cardijn, en las Juventudes Obreras Cristianas (Bruselas, Bélgica), confirmado de la página web http://www.joc.es/ web2/index.php/joc-es/joseph-cardijn. con una praxis que liga la fe y la vida, con un método comunitario e inductivo de ver, juzgar, actuar, al que posteriormente se le añadió evaluar y celebrar; una comunidad con un compromiso liberador $y$ promotora de la justicia $y$ los derechos humanos, especialmente, desde la opción por los pobres (como sujeto), asumiendo las consecuencias socio-políticas correspondientes (movimientos, organizaciones y luchas populares); vive la dimensión comunitaria de los llamados sacramentos, que liga y abre lo devocional a la responsabilidad social, política $y$ económica; es misionera por y con el protagonismo de los laicos, particularmente desde el trabajo pastoral y social de la mujer; crea experiencias de pluralidad religiosa, en especial, con las no cristianas y se articula para conformar redes de base.

El punto exacto de arranque de las llamadas СЕB, pareciera que no puede determinarse con precisión; sin embargo, es evidente que ante las necesidades pastorales hicieron que las comunidades empezaran a organizarse en torno a la vida sacramental. Algunas encontrarán sus inicios en Brasil, cerca de Río de Janeiro, ante la limitación de la presencia de sacerdotes o en Panamá, donde un grupo de sacerdotes de Chicago hicieron presente un trabajo pastoral semejante a la expresada en las Сев. Así empieza a propagarse por varios países como Argentina, Perú, Colombia, entre otros. Mientras que en Centroamérica, la misma situación conflictiva del Salvador y Nicaragua, fue favoreciendo el surgimiento de las СЕВ teniendo a sacerdotes jesuitas como sus promotores.

A finales de los años 60 hasta los años 80, el modelo había logrado amplia aceptación, aun cuando muchos sacerdotes se resistían a su presencia diocesana $y$ parroquial, ya sea por el compromiso pastoral o porque la misma comunidad mantenía una visión y dinámica tradicional; es decir, la separación entre fe y vida.

Con el paso del tiempo, estas comunidades fueron configurando una red que se extendió a toda América. Así, actualmente se encuentran organizadas y presentes en un Secretariado Ejecutivo Continental. Además existe el Consejo de consulta $y$ discernimiento, 
conformado por representantes de cada región. En el VI Encuentro Latinoamericano celebrado en México en 2004, las CEB quedaron configuradas en seis regiones.

TABLA 1

LAS CEB EN AMÉRICA LATINA

\begin{tabular}{ll}
\hline REGIONES & PAíSES \\
\hline Norte & México y Estados Unidos \\
Centroamérica & Guatemala, El Salvador, Honduras, Nicaragua, Costa Rica y Panamá \\
Caribe & Venezuela, República Dominicana y Haití \\
Andina & Colombia, Bolivia, Perú y Ecuador \\
Brasil & Brasil \\
Cono Sur & Argentina, Chile, Paraguay y Uruguay \\
\hline
\end{tabular}

Fuente: Elaboración propia con base en сев Conteninental 2014 (www.cebcontinental.org).

\section{MÉXICO}

La experiencia de CEB en México (CEB Conteninental 2014), puede ubicar sus inicios en los años 1967-1968 y se pueden considerar cinco grandes etapas. De 1967 a 1979, es la etapa de su origen y esparcimiento, ya que las experiencias de estas empiezan a observarse en todo el país. De 1971 a 1979, es el período de mayor impulso y se inicia un proceso de articulación a través de las asambleas y encuentros regionales y nacionales. Al respecto, Miguel Conchas considera que:

...el proceso de crecimiento de las CEB en México puede ser observado a través de los encuentros nacionales que han tenido lugar desde sus inicios. Es así como se han establecido ocho etapas. Veamos: la primera llega hasta los encuentros realizados en México (junio de 1972), en Celaya (agosto de 1972) y San Bartolo, Gto. (Septiembre de 1972); la segunda hasta los encuentros de Tepic y Plan de Ayala, Nay. (Junio y septiembre de 1973 respectivamente); la tercera está definida por los encuentros realizados en Tepeaca, Puebla (Enero de 1974) y en el Estado de México (mayo de 1974); la cuarta, marcada por el encuentro nacional de Morelia (mayo de 1975); la quinta se define en torno a las reuniones nacionales que tuvieron lugar en Taxco, Gro. (mayo de 1976) y en Progreso, Hgo. (Septiembre de 1977); la sexta etapa está señalada por el encuentro nacional que se desarrolló en abril y mayo de 1978, en torno a la III Conferencia del Episcopado Latinoamericano; la séptima estuvo marcada por los encuentros de México (1979) $y$ el de Nogales, Ver. (1980); y finalmente la octava etapa que se define con el encuentro celebrado en Tehuantepec, Oax (octubre de 1981) $(1988,160)$.

De 1980 a 1989, se encuentra una etapa de solidaridad y apoyo a los países en guerra o bajo crueles dictaduras, manifestándose así el mayor respaldo a los países de Centroamérica, El Salvador y Nicaragua. Además, se participa activamente en el movimiento popular. Hay una mayor articulación por medio de los equipos diocesanos, las asambleas y los encuentros regionales $y$ nacionales de frente a los grandes cambios a nivel social, económico, político y eclesial.

En este período es importante destacar la presencia activa de las CEB en los procesos electorales federales y estatales. Para el año 2000 , las comunidades ven la necesidad de un autodiagnóstico a nivel nacional para elaborar 
el diseño institucional de las CEB y su Planeación Estratégica 2002-2008.

\section{LAS CEB EN NAYARIT: ORIGEN Y DESARROLLO}

El origen y desarrollo de las CEB en Nayarit no pueden pensarse de manera aislada, pues comparten las mismas condiciones materiales de América Latina y expresan una gran sensibilidad y solidaridad con las comunidades de los países centroamericanos.

Su nacimiento mantiene un común denominador, en el contexto de pobreza y de marginación aguda de muchas localidades. Estas condiciones estructurales por sí mismas no generan la emergencia de las CEB, pero sí la alimentan. Por tanto, es necesario entender el compromiso social de los actores claves en la promoción de las llamadas comunidades, lo que explican la potencialidad que expresan y desarrollan a lo largo de su presencia.

\section{CONTEXTO SOCIO-POLÍTICO DEL SURGIMIENTO}

La situación política de los años 60 a los 90 se caracterizó por tres grandes horizontes temporales: el primero, la consolidación y auge de la hegemonía floresmuñocista (1946-1963); el segundo, la crisis floresmuñocista y la transición al cacicazgo emilista (1963-1981) y, el tercero, la consolidación y el auge de la hegemonía emilista (1981-1997) (Rea 2007 y Pacheco 1991). Estos horizontes están a la base de los distintos acontecimientos históricos que se fueron gestando, las distintas movilizaciones sociales en la ciudad de Tepic y con estas, el compromiso de los laicos que fueron configurando la CEB en la Diócesis de Tepic.

El gobierno de Gilberto Flores Muñoz se caracterizó por un cacicazgo violento, represivo, supresor de la disidencia social y política. Sin embargo, la nula institucionalización de la competencia y el conflicto interélites, interpartidista e interclasista, minó la capacidad del cacicazgo para adoptar oportunamente decisiones que fueran aceptadas socialmente $y$ que fueran consistentes en el tiempo.

Sin embargo, el debilitamiento y la crisis definitiva del cacicazgo floresmuñocista se ve marcada por la llegada de Julián Gascón Mercado a la gubernatura del Estado, la cual venía designada ya desde el centro del poder, por el Presidente Adolfo López Mateos. De igual manera sucedió después con Rogelio Flores Curiel, quien fue elegido por el Presidente Luis Echeverría Álvarez, después de los acontecimientos del 10 de junio de $1971^{21}$, cuando el Coronel Rogelio Flores Curiel renuncia como Jefe de la policía de la Ciudad de México (ibíd., 132). Además, Rogelio Flores Curiel llegó al gobierno del Estado en 1976, después del escandaloso fraude electoral, en el que soldados, policías y porros de la $\mathrm{Fe}$ deración de Estudiantes de Guadalajara (FEG) confluyeron en un gran operativo que tuvo como objetivo evitar el triunfo del candidato del Partido Popular Socialista (PPS) a la gubernatura del Estado: Alejandro Gascón Mercado (Periódico El Express 2011).

El Coronel Flores Curiel gobernó con mano de hierro y persiguió sin cuartel a los hombres $y$ mujeres que habían participado en el movimiento dirigido por Alejandro Gascón Mercado, en 1975. De manera que su régimen es recordado como "La Noche Negra", que duró 6 años, en los que disentir era un delito. Uno de sus brazos ejecutores era Antonio Sam López, ex director de la Policía Judicial del Distrito Federal (Severiano 2008).

Ante estos acontecimientos, la reestructuración del PRI en el Estado fue promovida y llevada a cabo por Emilio M. González, cuyo objetivo era recuperar para el sistema político en la entidad, el consenso perdido por el paso del régimen militar y fraudulento de Flores Curiel. A lo largo de su carrera política, Emilio M. González ${ }^{22}$ consolidó su poder en todo el Estado y afianzó el corporativismo y el populismo

21 Mejor conocido como el Halconazo o la represión estudiantil del Jueves de Corpus.

22 Emilio M. González inicia su carrera política en 1937 como secretario de la Confederación de Trabajadores de Nayarit (стм estatal). Fue cuatro veces diputado federal, en tres ocasiones fue senador y una vez legislador local. Dirigente del Partido Revolucionario Institucional-PRI estatal y gobernador de 1981 a 1987. Líder de la Cámara de Senadores en el sexenio de Carlos Salinas de Gortari (Narvaez, 27/03/2000). 
estatal, apoderándose de todos los frentes políticos en Nayarit.

Con este escenario político como trasfondo, se pueden destacar algunos acontecimientos sociopolíticos fundamentales en la década de los 70. Tal es el caso del inicio de la Universidad Autónoma de Nayarit (como proyecto de Universidad-Pueblo), el Instituto de Investigaciones Económicas, los movimientos populares emergentes y el sindicalismo independiente, los cuales dieron un particular matiz a la realidad del Estado.

Además, la problemática urbana de la ciudad de Tepic trajo consigo la presencia de la Comisión de Defensa Popular (CDP) y su influencia sobre el Movimiento Popular Urbano en Tepic. De modo que los acercamientos de la CDP se extendieron hasta los núcleos electorales. En este escenario, es importante también resaltar la presencia del movimiento estudiantil como resistencia a un Estado autoritario y la confrontación con el porrismo en el medio universitario.

Los años 80 estuvieron definidos por varias situaciones. Entre ellas, el afianzamiento de la organización territorial de Nayarit, los rezagos sociales, la lucha por suelo para la vivienda y el surgimiento del Movimiento Urbano Popular, especialmente en Tepic. Asimismo, emergen las experiencias de la Organización de Colonos e Inquilinos Independientes Cuauhtémoc (ocIIc) y la Organización Tierra y Libertad (OTYL), caracterizadas por sus formas de organización y acción, así como, la lucha en las calles $y$ los proyectos populares por la mejor calidad de vida en la ciudad, siendo otras de las expresiones claras del surgimiento de una sociedad crítica y consciente de su participación ante situaciones adversas.

Todo este proceso ciudadano se fue radicalizando también con el debate del sindicalismo democrático en la universidad, con la lucha social alrededor de la ciudad y su consecuente proyección al campo. Es así que se empieza a visibilizar distintas expresiones de inconformidad a través del movimiento campesino, los maiceros y tabaqueros, así como las rupturas al interior de las organizaciones del PRI que fueron configurando la movilización social de ese momento, al igual que la emergencia de la Unión de Ejidos Lázaro Cárdenas, del sur de Nayarit.

Para la década de los 90 es particularmente importante, tanto a nivel nacional como local, los reajustes en el modelo económico y la crisis política que afectó seriamente al sistema electoral. La reforma electoral, que si bien abrió cauces para las expresiones ciudadanas, marcó también trayectorias de incertidumbre en lo que refiere a la sociedad civil.

De igual manera, el debilitamiento del Estado como administrador del desarrollo trajo una serie de situaciones que modificaron la realidad de ese momento, principalmente en la zona norte de la entidad, al verse afectado los productores de tabaco con la reprivatización de la industria cigarrera y el beneficio del tabaco, en consecuencia se dio la desaparición de empresas paraestatales como TABAMEX, EXTAMEX $y$ Tabacos Azteca.

Algo similar sucedió con la producción y comercialización de café en el Estado y el cierre del Instituto Mexicano del Café, a consecuencia de los cambios ocurridos en el plano internacional. Por otra parte, la salida de SEPESCA de su participación en la producción acuícola y pesquera, así como su afectación a las familias de pescadores de los municipios de San Blas, Santiago, Rosamorada, Tuxpan y Tecuala, lo cual posteriormente dio paso a la instalación de otras empresas transnacionales. Mientras en la parte sur, aunque ya desde los años 70, el fideicomiso Bahía de Banderas se instaló como promotor de agresivos planes enfocados a atraer inversiones a la región, dando como resultado una tendencia gradual a la expropiación de suelo ejidal y su incorporación a manos privadas, principalmente a los inversionistas de la rama turística, con lo que además se ha ejercido un control centralizado por parte del gobierno federal, que da carta abierta para las acciones deliberadas de saqueo y desplazamiento de ejidatarios de la zona.

Todo lo anterior operó como marco para la aparición de algunos signos que presagiaban cambios en el escenario político y social; la emergencia de nuevos actores, un cierto ánimo de resistencia y una gran determinación en defensa de sus derechos $y$ mejores condiciones 
de vida. Así en la costa sur emergió un nuevo movimiento de resistencia ante el despojo de sus tierras y el desplazamiento sufrido a manos de inversionistas extranjeros apoyados por el mismo fideicomiso. Este movimiento se conformó por grupos de ejidatarios y sus familias, quienes fueron reprimidos a la fuerza por parte del gobierno en turno. Este fue el caso de Corral del Risco, en el Municipio de Bahía de Banderas, una comunidad que fue desalojada de sus tierras y reubicada en casas de dimensiones $y$ condiciones diferentes a las originales, ya que anteriormente sus casas eran más grandes $y$ contaban con posibilidades para la autosuficiencia, pues tenían corral con árboles frutales y/o animales domésticos.

La inestabilidad política y las tensiones manifiestas entre sociedad y el gobierno que dieron pie a la aplicación de políticas duras y represivas, dio la pauta también para que desde diferentes flancos fuera apareciendo un nuevo camino de actuación, es decir, el de los derechos humanos. En este momento se ve nacer desde organizaciones promovidas por grupos de la Iglesia Católica, nuevas expresiones de organización civil, como fue el caso del organismo Pro Derechos Humanos AC (PRODHAC), un proyecto apoyado directamente por el Obispo de la Diócesis de Tepic, Alfonso Humberto Robles Cota. Este organismo fue integrando personas de distintas procedencia, entre otros, líderes de opinión, profesionales de distintos campos, como un grupo de abogados y líderes naturales de organizaciones y movimientos sindicales, colonos, comerciantes y empresarios pertenecientes a los distintos organismos patronales de Nayarit. PRODHAC, pese a que abrió un frente de confluencia de intereses de los distintos grupos de condición política, no consiguió su consolidación, pues dentro de sí comenzaron a brotar líneas partidistas, misma que a su vez dieron fin al proyecto.

Desde el ámbito cultural se observaron sus contrastes al verse involucrados en toda esta dinámica algunas agrupaciones como la Comunidad de Artistas e Intelectuales de Nayarit AC (CAIN) y la Fundación Alica AC, las cuales podría decirse que fueron aporte cultural del importante grupo empresarial de Estado.
Estas son algunas de las condiciones en las cuales se originan y desarrollan las Comunidades Eclesiales de Base en el Estado de Nayarit.

\section{LAS CEB EN NAYARIT}

En Nayarit, en la Diócesis de Tepic fue donde emergió el compromiso signado desde la década de los 70 con la renovación religiosa. Fueron los sacerdotes diocesanos Gabriel García Ponce, Fidencio González Salcedo, Antonio Cortés, entre otros, quienes impulsaban esta visión del mundo. Sin embargo, se sumaron en esta tarea grandes personas, entre ellas comunidades de religiosas como las Madres Auxiliadoras, en Xalisco, Nayarit; las religiosas del Sagrado Corazón, en la colonia El Rodeo; las Siervas de los Pobres, en el Asilo de ancianos en Tepic, entre otras (os).

En 1983, bajo los auspicios del trabajo pastoral, fue posible la emergencia del primer grupo de lo que más adelante será la primera CEB en Nayarit, cuyo marco de expresión fue justamente los trabajos de Cuaresma y ejercicios espirituales de ese año. La jornada de "Solidaridad con Centroamérica", que consistió en dar a conocer la situación de Centroamérica y realizar un ayuno, además de recolectar dinero, celebrar la eucaristía y una marcha por el centro de la ciudad. Estas son las condiciones que vieron nacer formalmente a las primeras CEB.

En esta primera jornada, tres lugares fueron testigos de la emergencia de estos grupos: Las Colonias El Rodeo, la 2 de Agosto en Tepic y el Municipio de Xalisco. Lo cierto es que estas jornadas abrieron un nuevo horizonte a la gente de las colonias, con la cual se sienten hermanadas, identificadas y solidarias. Por lo que se preguntaron "¿es esto lo que Dios quiere de nosotros?”. Así empieza el caminar y la emergencia de las CEB en Nayarit.

El trabajo de quienes iniciaron esta labor se expandió en un segundo proceso, de tal forma que en términos territoriales $y$ de población no fue menor. Existieron CEB en 5 de los 19 municipios existentes en ese entonces en Nayarit: San Blas y Santiago, ambos en la costa del Estado y en zonas urbanas como Tepic, Xalisco y Santa María del Oro, vieron como era posible la organización social, de tal suerte que se configuró 
un tejido social que no solo cuestionaba las condiciones de pobreza en que se encontraban, sino que tenían una respuesta ante ella.

Es evidente que no bastaba con el ayuno o con las pláticas, derivadas de los ejercicios espirituales, sino que además había la necesidad de la acción concreta, la reconstrucción del tejido social local, ya que en la entidad existían condiciones de pobreza cada vez mayores. Para ello, las СЕв fueron organizando proyectos de economía solidaria, comercialización, cajas de ahorro, mutuales, medicina alternativa y de salud, pero sobre todo acciones de solidaridad con las causas justas de otros actores, tanto de manera local, regional y nacional.

Así, pues, ante la existencia de organizaciones sociales, por ejemplo, la ocic (Organización de Colonos e Inquilinos Cuauhtémoc 1981) $y$ en el caso de El Rodeo, la oEL (Organización de Ejidatarios Locales), el surgimiento de la CEB vinieron a fortalecer $y$ a potencializar la participación social y política de sus miembros, como testimonio del evangelio en medio de su realidad. Ya que la presencia de estas organizaciones, emergía de un señalamiento crítico del actuar estatal, a los oídos sordos del Gobierno del Estado, especialmente ante las condiciones infrahumanas en que se encontraban viviendo las familias. Por lo que la historia de las CEB, se $v a$ alimentando $y$ expresando de esa necesidad de organización social de grupos existentes:

Así, el 20 de enero de 1983 las religiosas auxiliadoras solicitaron en Asamblea del Sector 3 un lote para vivir, el cual se les otorgó por el voto de la gente. Aunque se tenía que esperar unos meses para que se entregara el lote, sin embargo, a las religiosas a los cuatro días ya tenían su lote y una casita de cartón de $4 \mathrm{~m}$ x 5m que había dejado una familia que se fue a sembrar al campo. Por lo que el 24 de enero, por la mañana llegaron Mónica Thieblin, Clara Delpin, María Elena Tinoco y María Guadalupe Gómez a vivir en esa casita de cartón, sin recurso alguno y sin experiencia en estos asuntos de lucha popular (Salazar y Yáñez, entrevista por Orozco, P., 05 de septiembre de 2006).
Estos lugares, derivado de su situación, presentaron más potencialidades para el surgimiento de un grupo de seglares comprometidos con su realidad, grupos animadores que empezaron a articularse con la actividad de los sacerdotes de la iglesia. Conviene señalar que al tener como marco de acción de la vida espiritual, las primeras acciones que se desarrollaron están acotadas inicialmente a las prácticas religiosas: cursos de iniciación parroquial, encuentros y retiros, espacios de apoyo mutuo, catequesis. La mayoría de ellos asociados a diferentes ministerios y servicios.

Como lo reconocen diversos analistas de la ciudad ${ }^{23}$, Tepic se ha distinguido por la tradición de organización y movilización que se construyó a partir de la década de los 70 . Anteriormente, las demandas sociales y la lucha política habían estado acotadas y encauzadas por estructuras y organizaciones corporativas, promovidas y auspiciadas por el Estado. Así, surgirán contra la correa de transmisión estatal, movilizaciones y organizaciones que dieron lugar a la toma de terrenos en la década de los 60, como fue el caso de la encabezada por Alejandro Gascón Mercado en el área conocida como "El Tecolote", Frente de Defensa Popular (FDP) o el mismo ocic; en general movimientos urbanos en defensa no solo de la vivienda, sino de sus condiciones sociales - aglutinadas en el llamado Movimiento Urbano Popular (Zepeda 1995 y 2005; Meza 1987).

Es interesante señalar las articulaciones que se lograron en el caso de las CEB en Nayarit, pues en el caso del sacerdote de la colonia El Rodeo, Gabriel García Ponce, se vio impactado por toda una experiencia pastoral realizada en el sureste mexicano, Chiapas, su contacto cercano con Centroamérica y Cuba, así como, su cercanía con Mons. Sergio Méndez Arceo y Mons. Samuel Ruíz, lo mismo que su proximidad a los trabajos de las CEB de las Diócesis de Ciudad Guzmán, Xalisco y Cuernavaca. Una visión que puede resumirse en los siguientes

23 Cfr. Meza, 1987 y Zepeda, 1995. Así también los profesores-investigadores de la Universidad Autónoma de Nayarit, Dr. Carlos Rafael Rea Rodríguez, Dra. Lourdes Pacheco Ladrón de Guevara, entre otros. 
términos: desde la necesidad de organizar para evangelizar $y$ responder a las necesidades humanas de las colonias recién formadas, buscando alternativas de vida, de mayor dignidad $y$ de justicia social.

Esta práctica llamó la curiosidad de un grupo de personas que integraron el movimiento popular naciente de corte progresista, pues al ver en las iglesias de El Rodeo, fotos, carteles y paneles de la guerrilla centroamericana y sobre todo, el firme compromiso de los cristianos con la solidaridad y liberación de esos países. Esto permitió lograr una cercanía y un diálogo entre quienes integrarían la CEB de El Rodeo.

El camino natural de la formación de las CEB en Nayarit transita de la fe hasta el convencimiento social, o la toma de conciencia de las condiciones de vida de las personas y de la comunidad, hasta hacer operativo este proceso de liberación, por medio de la generación de acciones sociales en beneficio de la comunidad y reestableciendo un tejido social que venía deteriorándose día a día. Se trata, en esencia de la formación de una comunidad al estilo de las primitivas comunidades (Hechos de los Apóstoles 2, 42).

Ese tránsito de la fe hacia espacios de vida más amplios no es, ni fue automático, ni tampoco está trazado de antemano, es más bien un producto social, una construcción social que pasa por diversos niveles de conciencia de la población. Reconocer y reconocerse con y desde el otro, desde una perspectiva espiritual hasta reconocer en la comunidad un espacio donde se articulan y construyen proyectos sociales y colectivos, no es cualquier cosa en las colonias de referencia.

Estas comunidades siempre estuvieron alejadas de la tutela estatal y municipal, dando paso de forma autónoma a la construcción de servicios públicos, la organización de panaderías, tortillerías, cooperativas de ahorro, mutualismo para servicios funerarios, espacios de salud y nutrición; pero fundamentalmente, a la construcción de sujetos políticos, lo que constituye quizá una diferencia sustancial con las instituciones formales $y$ funcionales. En este caso de la Iglesia y de algunas organizaciones populares, estas últimas animadas por el Estado o la misma jerarquía eclesial.
Una superación de las prácticas asociadas a la religiosidad tradicional se vio seguida por una serie de acciones encaminadas a proporcionar diversos ministerios y una lectura muy particular de la realidad. La emergencia de nuevas prácticas sociales, como la generación de espacios productivos $y$ sociales, pueden explicarse por la poca atención estatal y municipal. No obstante, su especificidad es la conformación de una verdadera comunidad que trasciende a la misma Iglesia.

\section{REFLEXIONES FINALES DE LAS CEB EN NAYARIT}

Las CEB en Nayarit tuvieron un éxito relativo desde el año 1983 hasta la entrada de la década de los 90 del siglo pasado, donde fue cambiando su radio de acción y el contexto en el que encontraban insertas. No obstante, dos dinámicas pueden explicar la crisis de la experiencia de las СЕВ. Ambas representan sendas paradójicas.

En el nivel externo, la articulación con grupos populares, si bien representó una ampliación de su radio de acción, también significó un reto que no se pudo superar: la integración no fue posible, las СЕв fueron rebasadas por los grupos populares. Por ejemplo, la emblemática Colonia 2 de Agosto fue ejemplar en este sentido, desembocó en pugnas internas y la creación de tres colonias en el noroeste de la ciudad (Tierra y Libertad, Venceremos y Prieto Crispín 1989), que no fueron sino la expresión de la incapacidad de articularse con los grupos populares y en las cuales la expresión de las CEB no solo se diluyó, sino desapareció por completo. Pero se desarrolló en otros campos de acción política, social y económica. Así, algunos grupos se identificaron con los partidos de izquierda, especialmente, con el Partido de la Revolución Democrática (PRD) o el Partido del Trabajo (PT), entre otros. Algunos más siguieron en el trabajo de las cooperativas en el Municipio de Xalisco; o en las mutuales y la panadería en El Rodeo; o el servicio de salud alternativa y de nutrición; o en las cajas de crédito a la Palabra (Caja Cero) en los municipios de Tepic y de Santiago Ixcuintla, respectivamente.

La segunda paradoja está en el nivel interno, al estar emergiendo de proyectos pastorales y anclada en el ejercicio teológico 
particular (TDL como proceso liberador no constitutivo solamente de los teólogos católicos, sino de esa pluralidad de reflexiones también protestante preocupada por la transformación de la realidad), una vez que los iniciadores de este proceso de comunidad, los padres Gabriel y Fidencio, entre otros y las religiosas (Las Auxiliadoras, de El Sagrado Corazón y de El Buen Pastor), dejan estos lugares de ejercicio de ministerio, se pierde la robustez de las СЕВ. Asimismo, las exigencias evangélicas y la reflexión teológica que orientaba al compromiso y a la acción social, se dejan de lado hasta mutar en acciones de menor impacto, acotadas a grupos de ayuda a los enfermos, recolección de despensas y visita a los presos; acciones pastorales que ya eran propias de algunos otros grupos de iglesia, como la Acción Católica y que solo promueven la asistencia social y no la transformación social propia de las CEB. Así lo expresan algunas personas que todavía mantienen su compromiso pastoral dentro de la iglesia:

Si y todavía, por decir nosotros si nos proponemos, vamos a las casas para que nos ayuden a ayudar a la gente más pobre, o si no, en nuestro grupo se programan actividades $y$ cada quien aporta con algo, ya sea para llevarlo a la iglesia, o aportarlo para alguien que necesita más que nosotros (Salazar y Yáñez, entrevista por Orozco, P., 05 de septiembre de 2006).

Además, la presión que se ejerció desde las cúpulas eclesiales no fue menor, donde el Obispo en turno, Alfonso H. Robles Cota, la cura diocesana $y$ algunos sacerdotes con una visión muy acotada y tradicional, así como, un bajo compromiso social, minaron los trabajos que ya estaban en franca decadencia o que tomaron un rumbo distinto al de sus inicios. Esta es la manera como lo ven algunos animadores de las CEB:

El sacerdote llegó como si hubiera venido a terminar con eso, porque era la iglesia la que promovió las comunidades eclesiales de base y él, como sacerdote, quería que eso se acabara, diciéndonos que esa línea ya no va... Abiertamente el obispo no nos dijo que tenía problemas con alguien, pero en el fondo nos daba el cortón, porque la colonia entre más, más crecía y la gente iba cambiando su manera de pensar, ya era de decir itenemos derechos $y$ vamos a hacer lo que sea hasta hallarlo!... Siguen insistiendo $y$ pues con muy pocos recursos, porque luego había que conectarse a las nacionales que había asambleas regionales y siempre había un animador diocesano a traer las actividades que se iban a hacer y cómo se va a trabajar en el año (Esperanza, entrevista por Orozco, P., 05 de septiembre de 2006).

Hoy pareciera que las CEB son solo referencia del pasado, que no embonan con el entorno actual del Estado en su conjunto. Sin embargo, la concientización adquirida en el transcurso de los años y el reconocimiento de su misión en la realidad presente, sigue haciendo que las CEB mantengan un caminar silencioso y firme, con la conciencia de conformar una red más amplia, a nivel regional (occidente), nacional e incluso internacional.

En suma, la aparente decadencia de las CEB se puede resumir en la centralización del control, la pérdida de protagonismo de los sacerdotes, la puesta utópica del reino en Centroamérica, como lugar temporal de un modelo bíblico-teológico, que al vivir un profundo reflujo, al ser apagado como faro de luz, significó la pérdida de un sustento importante y de la posibilidad de confrontación de un ejercicio pastoral tradicional, una alternativa distinta puesta en el contexto histórico-social de las comunidades.

\section{BIBLIOGRAFÍA}

LIBROS

Berryman, Phillip. 1990. Teología de la liberación. México: Siglo Veintiuno Editores.

Leñero Otero, Luis. 2003. "La Iglesia ¿disidente? de los pobres: el caso de las comunidades eclesiales de base en 
México sobre la pista de un cristianismo basado en la Teología de la Liberación". Debate actual sobre la Teología de la Liberación. México: Universidad Autónoma Metropolitana (UAM).

Rowland, Christopher. 2000. La teología de la Liberación. Lóndres: Cambridge University Press.

\section{PUBLICACIONES PERIÓDICAS}

Boff, Leonardo. 1988. Y la Iglesia se hizo pueblo. Eclesiogénesis: la Iglesia que nace de la fe del pueblo: 119-129.

Concha, Miguel. 1988. "Las comunidades eclesiales de base y el movimiento popular". Revista Dialéctica 19: 159 165. Acceso el 06 de enero de 2011. http://148.206.53.230/revistasuam/ dialectica/include/getdoc.php?id=344\&ar ticle $=365 \&$ mode $=$ pdf.

Gutiérrez, Gustavo. 2007. "Pobreza y reflexión teológica". Le Monde Diplomatique. Acceso el 12 de diciembre de 2010. http:// www.lemondediplomatique.cl/Pobreza-yreflexion-teologica.html.

Narvaez Robles, Jesús. 2000. "Los emilistas se apoderan de todos los frentes políticos de Nayarit". La Jornada, 27 de marzo.

Pacheco Ladrón de Guevara, Lourdes. 1991. "Elecciones municipales en Tepic en 1990”. Revista Iztapalapa 23: 117-130.

Pastor, Raquel. 2008. "Católicos inspirados en la Teología de la Liberación redefinen su identidad". El Cotidiano 149, n. ${ }^{\circ} 23$ : 96-100.

Periódico El Express, jueves 21 de Abril de 2011, acceso el 21 de abril de 2011. http:// www.Express.com.mx.

Rea Rodríguez, Carlos Rafael. 2007. "El gasconcismo: surgimiento de una cultura política". Desacatos. Revista de Antropología Social, septiembrediciembre.

Richard, Pablo. 1995. "La fuerza del Espíritu. Religión y Teología en América Latina”. Nueva Sociedad 136: 128-141.

Severiano Ocegueda, Héctor. 2008. "Flores Curiel". El tiempo de Nayarit, 31 de octubre.
Zepeda López, Salvador. 1995. "MUP y Cultura Política en Tepic". Revista de Investigación 1.

TESIS NO PUBLICADAS

Meza Ramos, Eduardo. 1987. "Corporativismo estatal y movimiento urbano popular en Tepic (1970-1987)". Tesis de Licenciatura. Universidad Autónoma de Nayarit.

\section{TEXTOS ELECTRÓNICOS}

СЕв Continental. "Comunidades Eclesiales de Base". Accceso el 18 de enero de 2014. http://www.cebcontinental.org.

Juventud Obrera Cristiana. Joseph Cardijn (fundador). Acceso el 18 de enero de 2014. http://www.joc.es/web2/index.php/ joc-es/joseph-cardijn.

Romo Cedano, Pablo. 2006. Teologías de la Liberación. Instituto de Investigaciones Sociales (IIS) de la Universidad Nacional Autónoma de México (UnAm). Acceso el 20 de enero de 2014. http://conceptos. sociales.unam.mx/conceptos final/482trabajo.pdf?PHPSESSID=33ead 3d1e53dd47a9eb21b2ac78a4fe0.

\section{ENTREVISTAS}

Esperanza (miembro de la CEB colonia El Rodeo), entrevista 3 por Orozco, P. el 05 de septiembre de 2006.

García, Pedro (Presidente de Acción Ciudadana), entrevista 2 por Orozco, P. el 05 de septiembre de 2006.

Mondragón, Mariela (miembro de la CEB colonia El Rodeo), entrevista 4 por Orozco, P. el 05 de septiembre de 2006.

Salazar, Eusebio y María del Refugio Yáñez (miembros de la CEB de las colonias de El Rodeo y de La 2 de Agosto), entrevista 1 por Orozco, P. el 05 de septiembre de 2006.

Sánchez, Gabriel (miembro de la CEB colonia 2 de Agosto), entrevista 5 por Orozco, P. el 05 de septiembre de 2006 . 
OTROS

Consejo Episcopal Latinoamericano. 1968. II Conferencia del Episcopado Latinoamericano. Medellín, Colombia: Consejo Episcopal Latinoamericano (CELAM).

Consejo Episcopal Latinoamericano. 1979. III Conferencia del Episcopado Latinoamericano. Puebla, México: Consejo Episcopal Latinoamericano (CELAM).

Consejo Episcopal Latinoamericano. 1992. IV Conferencia del Episcopado Latinoamericano 61, 95, 259. Santo Domingo, República Dominicana: Consejo Episcopal Latinoamericano (CELAM).

Consejo Episcopal Latinoamericano. 2007. V Conferencia del Episcopado Latinoamericano 178, 193.Bogotá,
Colombia: Consejo Episcopal Latinoamericano (CELAM).

Pablo VI. 1965. "Encíclica Gaudium et Spes (GS)". Concilio Vaticano II. Vaticano, Roma: Ed. Vaticano.

Pablo VI. 1965. "Encíclica Lumen Gentium $(L G)$ ", Concilio Vaticano II. Vaticano, Roma: Ed. Vaticano.

Pablo VI. 1967. "Encíclica Populorum Progressio".Vaticano, Roma: Ed. Vaticano.

Zepeda López, Salvador y Erick Castillo B. 2005. La acción gubernamental ante el crecimiento urbano en el Valle de Matatipac. Mitos y realidades en el área conurbada Tepic-Xalisco (1980-2005). Mimeo.

Fecha de ingreso: 04/02/2014 Fecha de aprobación: 20/03/2015 